\section{What companies can learn from unicorn startups to overcome the COVID-19 crisis}

\author{
Cristina Doritta Rodrigues and Matheus Eurico Soares de Noronha \\ Escola Superior de Propaganda e Marketing, PPGA/ESPM, Sao Paulo, Brazil
}

\begin{abstract}
Purpose - This paper aims to search measures that unicorn startups have implemented during the pandemic and show what lessons can be learned to help entrepreneurs and small and medium businesses to overcome the crisis.

Design/methodology/approach - The method is a multiple case study with five unicorn startups. This study collected data through interviews and analyzed them by the content analysis technique.

Findings - The findings show that the pandemic affects negatively unicorns' businesses; that a digital business model innovation affects them positively; and that innovations moderate positively the negative impact of the crisis.

Research limitations/implications - Most interviewees hold operational positions.

Practical implications - Three actions stand out to overcome the crisis: adoption of new digital platforms; strategies to increase the network of partners; and adaptations in the provision of payment services.

Originality/value - The cases show that entrepreneurs and small and medium enterprises need to develop capabilities to innovate in their business models, and digitalization is a solution to face the crisis and overcome it in the future.
\end{abstract}

Keywords Unicorn startups, Business model innovation, Covid-19

Paper type Research paper

\section{Introduction}

It is not yet possible to measure the impacts already caused and yet to come by the Covid-19 pandemic. Large, medium and small companies were immediately struck, and this impact tends to last (Nassif, Corrêa, \& Rossetto, 2020; Priyono, Moin, \& Putri, 2020; Bărbulescu, Tecău, Munteanu, \& Constantin, 2021). While some companies struggle to resume normal operations, owing to strict isolation policies implemented by governments (Liguori \& Winkler, 2020; Lee \& Trimi, 2021), others, such as innovative and unicorn startups, are taking new steps to keep active in the crisis and try to overcome it (Ketchen \& Craighead, 2020; Kuckertz et al., 2020; Bărbulescu et al., 2021).

(c) Cristina Doritta Rodrigues and Matheus Eurico Soares de Noronha. Published in Innovation \& Management Review. Published by Emerald Publishing Limited. This article is published under the Creative Commons Attribution (CC BY 4.0) licence. Anyone may reproduce, distribute, translate and create derivative works of this article (for both commercial and non-commercial purposes), subject to full attribution to the original publication and authors. The full terms of this licence maybe seen at http://creativecommons.org/licences/by/4.0/legalcode

This study was financed in part by the Coordenação de Aperfeiçoamento de Pessoal de Nível Superior - Brasil (CAPES) - Finance Code 001.
Unicorn startups to overcome the COVID-19 crisis

Received 21 January 2021 Revised 26 February 2021 Accepted 26 March 2021 
Despite great digital mobility, flexibility, capacity to allocate assets promptly, competence to innovate quickly and ability to attract different forms of investments (De Massis, Frattini, \& Quillico, 2016; Hogarth, 2017), unicorns also face challenges that can be seen as new opportunities and learning (Dalmarco, Maehler, Trevisan, \& Schiavini, 2017). They foster managers to act differently, by innovating their business models (Nunes \& Russo, 2019) and putting into practice new measures to create value for customers (Kuckertz et al., 2020).

In specific segments, unicorn startups saw a huge increase in demand, but the economic downturn caused by the pandemic affected production and supply chains (Kuckertz et al., 2020; Ketchen \& Craighead, 2020). It also affected chains from sectors not directly linked to unicorns' activities (Ratten, 2020), which have come to need their services more intensely (Anthony \& Abbas Petersen, 2020; Ketchen \& Craighead, 2020; Bărbulescu et al., 2021).

The crisis also drove entrepreneurs and managers to provide products and services with the support of responsive digital platforms (Anthony \& Abbas Petersen, 2020; George, Lakhani, \& Puranam, 2020). For some of them, this required a rapid change of their business models, which accelerated digital transformation (Ketchen \& Craighead, 2020; Kudyba, 2020; Soto-Acosta, 2020; Priyono et al., 2020; Bărbulescu et al., 2021; Lee \& Trimi, 2021).

Since unicorn startups have abilities to face critical factors (Dalmarco et al., 2017) with greater flexibility, the analysis and identification of what this type of company has done to overcome the crisis (Kuckertz et al., 2020) can help entrepreneurs to make decisions for keeping their businesses, in addition to providing a unique opportunity to build knowledge (Ketchen \& Craighead, 2020).

Unicorn startups are a new phenomenon; however, they have received almost no attention from the academic community. Some studies address this type of company superficially, by mainly using old and outdated management theories (Jinzhi \& Carrick, 2019).

Regarding business model innovation (BMI) in digital startups, essentially in established startups (Sushandoyo, Kencanasari, \& Prasetio, 2020), innovation through reconfiguration is a little discussed topic and a developing field (Massa \& Tucci, 2014; Amit \& Zott, 2015; García-Gutiérrez \& Martínez-Borreguero, 2016; Wirtz, Pistoia, Ullrich, \& Göttel, 2016). Nunes and Russo (2019) highlight the shortage of studies on BMI in the international context, and mention the absence of research involving Brazilian companies.

To call academy's attention to unicorn startups and assist in understanding business model reconfiguration, the research problem aims to answer: What are unicorn startups doing to overcome the Covid-19 crisis? The objective is to seek measures that these companies are implementing during the pandemic and draw lessons to learn for helping entrepreneurs and small and medium enterprises (SMEs) to overcome the crisis.

The research is relevant for several reasons. It addresses the impacts of Covid-19 on unicorn startups; focuses on an emerging phenomenon and on learning from the measures they have implemented; shows the importance of digital BMI, practiced by companies in an emerging market - Brazil; and contributes to management practice, by highlighting three actions that entrepreneurs and SMEs managers should take to cope with the crisis. These are the adoption of new digital communication platforms to accelerate the information flow; strategies for increasing partners' network and meet logistics and execution demands; and adaptations in the provision of payment services. 


\section{Theoretical framework}

Unicorn startups

Startups are firms oriented towards a fast growth, which reach the speed through special forms of funding, such as business angels, seed capital firms and crowdsourcing, among others. They represent a high-risk model with considerable turbulence and volatility (Condom-Vilà, 2020); therefore, entrepreneurs are seeking changes actively and constantly, or making strategic choices, to overcome the problems they face and lead them to business success (Hormiga, Xiao, \& Smallbone, 2018).

At least, the following four common resources explain unicorns' success:

(1) their small size, which facilitates strategic decision-making and implementation of quick practical measures;

(2) their founders and leaders are usually experienced entrepreneurs, who have often dealt with high-risk situations and failures;

(3) they are financed by venture capital companies, which pressure them for the quick development of a new business, and foster innovation and launching of new products or services; and

(4) innovations offered to target audiences are digital, which reach the market leveraged by digital platforms widely disseminated through social networks; that is, much faster than traditional businesses that struggle and invest in the conventional marketing of products/services (De Massis et al., 2016).

Among startups' categories, the term unicorn refers to the category of private high-growth startup companies, worth one billion dollars or more (De Massis et al., 2016; CBInsights, 2020; Gornall \& Strebulaev, 2020), plus appreciation within a few years of their inception (Jinzhi \& Carrick, 2019) and highly innovative (Dellermann, Lipusch, Ebel, Popp, \& Leimeister, 2017).

Currently, there are more than 400 unicorns around the world. The majority is concentrated in the USA (222) and China (182). Although the number of Brazilian unicorns seems small (12), it is higher than in other emerging and developed countries, such as South Korea (10), Israel (09), France (05), Indonesia (05), Switzerland (04), Singapore (03), Australia (03), Japan (03), Hong Kong (03), Sweden (02), Canada (02), Colombia (02), Spain (02), Holland (01), Luxembourg (01) and Portugal (01) (CBInsights, 2020; StartupBase, 2020).

There are seven Brazilian firms ranked by CBInsights (2020), considered the ultimate list of unicorn companies (Gornall \& Strebulaev, 2020). These are Nubank, classified as fintech, operating in the financial market; Wildlife Studios, which acts in the mobile games segment; $i$ Food, rated in the supply chain, logistics and delivery, which operates in the e-commerce market; Loggi, classified in supply chain, logistics and delivery, which acts in the logistics and urban mobility market; QuintoAndar, rated as e-commerce and direct-to-consumer, which operates in the real estate market; $E B A N X$, graded as fintech, which acts in the finance market; and Loft, classified as e-commerce \& direct-to-consumer, which operates in the information and communication technology and telecom market. To complete the list, StartupBase (2020) ranks five other Brazilian unicorns: PagSeguro, operating in the finance market; 99, which acts in transportation; Stone Payments, which operates in the finance market; Arco Educação, which acts in the education market; and Gympass, which operates in the health and well-being market.

\section{Impacts of the Covid-19 crisis on startups and innovation in digital business models}

The entrepreneurship literature does not have a specific guideline for dealing with the unique situation caused by the pandemic. However, issues such as crisis management, 
which addresses how companies respond to a crisis and their adaptability, are a good path to look for answers (Priyono et al., 2020; Ratten, 2020; Kuckertz et al., 2020).

The high negative impact of the crisis on startups' businesses worldwide has caused $70 \%$ of these companies to terminate employment contracts, leaving them with operational resources sufficient to face it a few more months, as of July 2020 (Bărbulescu et al., 2021).

In Germany, innovative startups were immediately struck by the crisis, with sales decrease but keeping fixed costs, which brought a real threat to liquidity and long-term survival. In addition, there was an unfavorable climate for innovation, paralyzed markets and access barriers to funding, which made them adjust their organizational structure abruptly, to resist (Kuckertz et al., 2020).

American and Brazilian unicorns also experienced negative impacts. Uber, Airbnb, Gympass and 99 had steep declines in their demands, and consequently, in their revenues; in some cases, they reduced fixed costs by cutting work teams (Ribeiro, 2020; Riveira, 2020; Cilo, 2020; Lima, 2020; Ingizza, 2020). In view of this evidence, we propose the following proposition:

P1. The crisis caused by Covid-19 affects negatively unicorn startups' businesses.

Companies must act quickly (Priyono et al., 2020), and the answer will determine the ability to have a business model that survives in this setting (Ratten, 2020). It is essential to prepare firms for crisis management. Owing to their characteristics, innovative startups, and especially unicorns, may be better prepared to deal with this situation, considering that innovation is a prerequisite to adapt, identify and seek entrepreneurial opportunities through internal restructuring or business model adjustment (Linnenluecke, 2017; Kuckertz et al., 2020; Ratten, 2020).

Unicorns are able to respond dynamically to adversity, especially because they can adapt BMI for making specific digital innovations as solutions to meet market needs quickly. This is because the business model is built around a single digital platform or software, which is very fast and cheap to develop and promote (De Massis et al., 2016).

BMI in digital startups is a gap in the literature. It is an important step for digital startups to survive in the initial stage of their journey (Sushandoyo et al., 2020), but should not be restricted to that phase. It is continuously necessary, especially for adopting innovative strategies or redefining the strategy to withstand crises, by seeking economic results different from those already used.

This argument follows Amit and Zott (2015), who discuss BMI in established companies. However, their ideas are applicable to entirely new BMI and to company managers who need to adapt their business models incrementally, aiming to reach a new BMI for the organization from what already exists, by making small changes to improve performance, features or applications (Norman \& Verganti, 2014).

For this reason, instead of using the term "design," we think that the most correct is "reconfiguration" (Cahen \& Borini, 2020), as "design" refers to new business models for newly created organizations, including the entrepreneurial activity of creating, implementing and validating a business model. The term "reconfiguration" regards the phenomenon by which managers reconfigure organizational resources and acquire new ones to change an existing model. This is in line with Nunes and Russo (2019, p. 24), who consider BMI "a new configuration, due to changes in the way company proposes, develops, and delivers to its consumer." Thus, the reconfiguration process requires changing from an existing model to a new one (Massa \& Tucci, 2014). Therefore:

P2a. BMI through reconfiguration affects positively unicorn startups' businesses. 
BMI can also be a complement to product and process innovation (Johnson, Christensen, \& Kagermann, 2008; Amit \& Zott, 2015). Because it is a less uncertain and expensive option, it tends to become a sustainable performance advantage, given the difficulty of competitors to imitate, thus being a potentially powerful tool that allows managers to solve the trade-off between innovation costs and benefits.

This is because BMI addresses how managers negotiate with their customers, partners and suppliers in new systems of activities that create value. Thus, even in conditions of resource shortage, organizations do not need to renounce innovation to improve their performance perspectives (Amit \& Zott, 2015), because BMI is not a matter of ex-ante superior prediction, as it requires trial, error and ex-post adaptation (Chesbrough, 2010). Therefore, BMI can be an ex-post tool, which gives the company a chance to create a new market or explore new opportunities in existing markets, thus mitigating the negative effects of the crisis. Hence:

P2b. BMI through reconfiguration moderates positively the crisis's impact on unicorn startups' businesses.

The theoretical model in Figure 1 shows the interrelationships of the propositions.

\section{Methodology}

Considering the emergence of the studied phenomenon, the approach is qualitative and exploratory. The method is the multiple case study, which follows Yin's protocol (2015). To select the cases, we used the following criteria: the startup should be a Brazilian unicorn and should have implemented new measures to face the pandemic.

By applying these criteria, we selected the unicorns most cited in public news, considering their coping with Covid-19, and made a call through social networks, asking managers, analysts and other employees to provide their contacts to participate in the research through online interviews. We chose the judgmental sampling criterion to select the firms (Marshall, 1996).

We selected five unicorn startups. To preserve their identity, we adopted the pseudonyms Company A, Company B, Company C, Company D and Company E. As there are 12 unicorns in Brazil, the chosen companies represent a response rate of $42 \%$. Table 1 shows some attributes of these unicorns.

We collected primary data between May and June 2020, through ten in-depth individual interviews with managers and analysts; interviews were online, recorded and transcribed, and took between 10 and 30 min, generating a 48-page report. To do the interviews, we followed a semi-structured script (Yin, 2015), which addressed the following topics: digital business model, business model adaptation and innovation in the pandemic. Table 2 describes the sample.

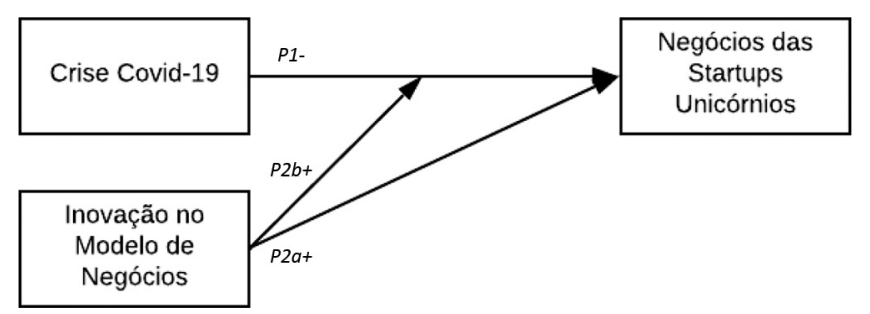

Figure 1. Theoretical model 
INMR

Table 1.

Description of the investigated unicorns
To strengthen the empirical evidence of primary data (Yin, 2015), we collected secondary data.

We applied the content analysis technique by following the steps outlined by Krippendorff (2004). Thus, for data building, we carried out unitization, sampling, recording and coding and reduced data to manageable figures, with the assistance of Atlas.ti software.

The categories defined were business model and new measures implemented during the crisis. We chose the semantic criterion for the analysis of the categories, by which we count the repetition frequencies in each category, to show the relevance and the number of repetitions of these topics (Krippendorff, 2004). The number of repetitions for the category "digital business model" was 145, and for "new measures adopted during the crisis" was 177, which indicate their relevance. They emerged from the theoretical framework and interviewees' reports.

Next, we carried out the phenomenon's abductive inference (Krippendorff, 2004), based on the analytical building of the theoretical model (Figure 1). We analyzed the relationships between the categories, by describing the results, followed by discussion. Finally, we achieved the answer to the research question (Krippendorff, 2004), explaining the practical contribution of the findings in pointing changes in the digital business models of these companies, through the implementation of the new measures adopted to mitigate the crisis.

\begin{tabular}{lccl}
\hline Company & Year of foundation & Year it became a unicorn & Segment \\
\hline A & 2013 & 2018 & Fintech \\
B & 2012 & 2019 & HR Tech \\
C & 2012 & 2019 & Proptech \\
D & 2012 & 2018 & Fintech \\
E & 2012 & 2018 & Mobility
\end{tabular}

Source: Prepared by the authors (2021)

\begin{tabular}{lllll}
\hline Interviewee & Company & Position & Department & Date \\
\hline I1 & A & Customer Experience & Xpeer & May 2020 \\
I2 & A & Business Operator & Xpeer & May 2020 \\
I3 & A & Customer Experience Analyst & Xpeer & May 2020 \\
I4 & B & Global Marketing and Content Senior & Marketing & June 2020 \\
I5 & C & Analyst - B2B & Customer Service & June 2020 \\
I6 & C & Credit Analyst & Operations and & May 2020 \\
I7 & C & Community Manager & Finance & Marketing \\
I8 & D & Key Account Manager & Executive & June 2020 \\
I9 & D & District Logistics Leader & Account Services & June 2020 \\
I10 & E & Service Analyst & Logistics & Internal Service \\
Source: Prepared by the authors (2021) & May 2020 & \\
\end{tabular}

Table 2.

Sample

Source: Prepared by the authors (2021) 


\section{Results}

Company A

Company A provided an amount of resources from the marketing department to help customers with problems during the crisis. "The company provided $\mathrm{R} \$ 20$ million from our marketing budget to help customers in difficulty [...] the customer service team was responsible for checking what customers needed, in order to help them" (I3). This is confirmed by I1, who highlights the agility of the project development, implementation and communication.

The customer service team also loosened payment deadlines:

[...] we reshaped all invoice installments, delays, interests, precisely because of this [the pandemic and customers' income decrease]; one factor that we considered was to deposit an amount in the account for the client to buy food (I3).

On service innovation, I2 says:

[...] we started to implement new renegotiation rates for personal loans with up to 60 days of grace-period. New partnerships with supermarkets and bank representatives to achieve a new and innovative form of making invoice, bill, and deposit payments. We recently created a new product, which is the invoice payment in installments, with values of up to $1.9 \%$ interest (I2).

I1 mentions the same innovations, in addition to new partnerships with stores that are still open for receiving payments. Thus, the reach of Company A's partnerships leverages mechanisms for mitigating impacts on its cash flows, besides aiming a greater access and the financial well-being of users.

To face the pandemic, the company implemented home office for all employees:

[...] the company sent chairs, armrests, keyboards, monitors, from the workplace to employees' homes, so that they could work comfortably. I believe that this not only influenced employees, but also customers, by decreasing the number of people on the streets to reduce the risk (I3).

I1 and I2 confirmed I3's speech regarding home office.

Company A offered assistance, distance training and qualification to anyone who needed this support to keep activities in home office, using the Slack tool and holding meetings by videoconference (I1; I3).

All these new measures took into account the changes in the national scenario resulting from the pandemic, and "served to shape what we have today as a product, and improve what we already deliver" (I2). In addition, the new measures enhanced Company A's work processes "[...] we are managing to get more time to invest in the actions we are taking, in a faster and more practical way" (I2).

Interviewees' reports show that the crisis affects negatively Company A's customers, and consequently, their businesses, supporting $P 1(P 1)$, which led the company to adopt different measures and innovations, reconfiguring its business model so that its flows are less affected during the pandemic, which supports $P 2 a(P 2 a)$.

The quick creation of new products/services and the company's flexibility and adaptation reflect positive solutions that minimize the negative impact of the pandemic, as they facilitate banking transactions and users' payments. In addition, BMI by reconfiguration made Company A increase its scalability through new partnerships, adding incremental innovations to existing services, to retain users and encourage consumption behaviors. Therefore, BMI actions implemented to mitigate the negative effects of the crisis moderate positively the impact on financial flows that Company A would suffer in case of inertia, and create new value proposals for customers, supporting $P 2 b(P 2 b)$. 
Company $\mathrm{B}$ bet on the integration of partnerships and use of online platforms to continue developing content and classes for its subscribers:

[...] one of our initiatives was the integration with several other CSMs [Customer Success Manager], mindbody, evo, glofox [...] platforms already used by our partners, enabling the transmission of recorded and online classes also for non-students (I4).

To assist its partners, Company B:

[...] launched live classes by streaming, both on YouTube and Instagram; on Zoom [...] the person schedules through the application and receives the link on the specific day and time [...]; they receive a notification and practice live and online through our partners (I4).

One of the innovations made in mid-May was launching a program within the platform "[...] which is a benefit, there is no extra cost, and it gives access to a series of applications for training, meditation, yoga, nutrition plan, even online psychologists" (I4), which is available to all companies - and their employees - that hire plans with Company B.

These technological solutions were implemented to increase communication and customers and partners' retention linked to the digital platform (I4; Cilo, 2020), so that "everything is online, digital, and on demand" (I4), as a way of keeping contracts in view of the closing of establishments and to minimize the negative impacts of the crisis on customers and on Company B's revenue.

The crisis drove Company B to implement and spread new measures to "[...] support both our partners that are fitness centers and studios, to make them still generate income, and also to customers" (I4).

Despite the positive reports from I4 and the effectiveness of the implemented measures, Cilo (2020) shows that there was a decrease in health clubs' revenues and suspension of users' plans that affected Company B, leading to employee cutbacks. These data support $P 1$, showing the negative impact caused by the crisis on Company B. However, it arranged its services by expanding possibilities between platform partners and end users through new programs and digital consulting with nutritionists and psychologists, online classes, thus supporting P2a. Hence, BMI brought a positive impact to Company B's business with technological and digital improvement. As it implemented the reported measures innovatively, it managed to reduce customers' loss by offering new products and benefits online, thus supporting $P 2 b$.

\section{Company $C$}

Company $\mathrm{C}$ made partnerships with startups to collaborate with the logistics process and support employees and customers. Applications such as Loggi and Picpay support the real estate rent service provided by Company C, which suspended on-site visits (I7). Loggi collaborates by delivering the keys, while visits are made through online photos and videos (I5; I6; I7). Picpay is used to loosen payments and installments of rents managed by Company $\mathrm{C}$, enabling users to honor their obligations (I5).

Regarding the actions adopted, "the main thing that changed was the flexibilization of rent payment, by providing discounts" (I7) and "installment payment of bills" (I6); thus, the company became "[...] very empathetic, listening to everyone, and treating each problem as unique and individual [.. .] we are looking at each case to offer the best possible solution” (I7). 
Concerning the support to partners and employees, Company $\mathrm{C}$ made a partnership with "Dr. Consulta" through an application that allows carrying out necessary consultations and supporting its employees, including dependents, who can test for Covid-19 (I7).

"Process innovation helped us adapt our whole work model to be the home office" (I7). Company $\mathrm{C}$ offered help and support for "those who do not have a comfortable chair at home, who have problems with the internet, or do not have access to it; there was a team just to assist with that, to install, configure, etc." (I7).

Business model reconfiguration for the home office has brought benefits such as:

[...] a high growth in most processes, with this we reduced by $40 \%$ the average of delays in the first hour, that is, the whole team is ready to start the service at the beginning of the day. We were also able to better define the topics and the need for meetings, we managed to be more punctual at meetings, $[\ldots]$, so we have been much more assertive, [...] and it has been positive for the organization (I6).

In addition, the pandemic accelerated the improvement of Company C's internal work tools "[. . .] internally, our screens were highly improved [...], so that we could work better [...], they managed to make the platforms briefer and informing what we really need" (I6). Internal communication was enhanced "[ . . . by using tools such as Slack, chat, and e-mail" (I7).

Payments continued normally, for employees and partners, despite no on-site visits, new contracts, or employment relationship (I7). Company $\mathrm{C}$ also pays the rent values to the owners, regardless of the tenants' financial situation, and has committed, in case of default, "not to evict them, or do anything extraordinary at this moment" (I5).

Company $\mathrm{C}$ created two innovative solutions, essential to continue its business: the Virtual Broker and the immediate FAQ (a chat) for questions and answers. The Virtual Broker strengthens the technological base by maximizing processes and activities. On the platform, the "talk to the broker directly" button replaced the "visits" button (I5; I6; I7). This virtual broker appears in all real estate ads, "it is a direct button that opens WhatsApp" (I5), starting a conversation between potential customers and brokers:

With the virtual broker it is possible to clear all customers' doubts directly on the platform, without needing another tool [...] people are enjoying this new method. It's working really well, our credit analyses have increased a little bit, because in the first and second weeks after the pandemic decree they fell (I6).

The crisis negatively affects the real estate brokerage sector, which supports $P 1$. Company $\mathrm{C}$ responded quickly by implementing flexibilization of payments and virtual brokerage, which reduced its revenue losses, thus supporting $P 2 \mathrm{a}$ and $P 2 b$. Therefore, $P 2 a$ and $P 2 b$ are supported by interviewees' reports that show BMI implementation through incremental reconfigurations, such as digital buttons, online service, partnerships and improvement of internal tools that did not exist before the pandemic, and had a structural and positive impact on its business.

\section{Company D}

Company D decided to soften the obligations of entrepreneurs and micro-entrepreneurs - "to help the customer in these difficult times, we waived the monthly fees" (I9). It was necessary to soften payment invoices, since several businesses registered at the company would have an exponential drop in their revenues and invoicing (I9).

Regarding the new business practices, Company D decided to help small entrepreneurs "the company provided $\mathrm{R} \$ 30$ million in microcredit, precisely to help these entrepreneurs not to break and close their doors" (I9). 
Other measures implemented were changes in software and tools, "they [Company D] made some system improvements, like VPN, and in tools, with virtual rooms, and communication channels through Workplace and Slack" (I8). Workplace, a digital application that makes corporate contact instantly, supports customers. The Slack platform makes internal and external communication, which provides efficient information exchange between companies and other commercial relationships, with the possibility of creating new channels within the platform, which strengthens the relationships (I8).

Regarding service innovation, "the most innovative was discovering new work methods instead of door-to-door [phone, e-mail, WhatsApp, applications], since we cannot make visits" (I9). Company D adopted partial home office on a scale system, and $25 \%$ of the employees are on the streets because the business model is digital, but has operations related to physical retail.

We had to adapt to this type of business because we suffered a lot from this change, but we tried to do it in a way that customers would not feel (I9).

As a result, we implemented measures of restraint and basic care for employees who provide support or make exchanges with customers, who continue to receive support and choose where they will be served, with preference for customers of delivery, physical stores, and emergency establishments (I9).

"Another innovation was the new product that is booming, it's an application very easy to handle, we provide step-by-step tutorials quick and brief" (I8). The application is a new product launched by Company D during the pandemic, which allows making sales in social networks, in cash or installments, without the need of a website or a payment machine.

Company $\mathrm{D}$ allocated resources for communication and marketing by making advertisements and actions with celebrities and singers. Before the pandemic, marketing was only through word of mouth (I9). Company D started investing in lives on YouTube and sharing them on social networks, expanding their reach, attracting users and new microentrepreneurs, through Facebook, Twitter, and Instagram (I9).

The crisis negatively affected Company D because it reached customers that use its digital payment machines and services, which supports P1. Adherence to new communication platforms, as well as launching a new product that reaches new customers, without the need to provide credit card machines in loco, represent BMI by reconfiguration, supporting $P 2 a$. The new product launching, flexibilization of fares, monthly fees and loans to entrepreneurs, to be paid with interests, moderate the future financial impacts that the pandemic may cause, thus supporting $P 2 b$.

\section{Company E}

Company E has contributed US\$10m to offer support to drivers and partners diagnosed with Covid-19. "[...] as it was published in the media, the platform provided these funds to the driver diagnosed with Covid-19" (I10). It also "provided vehicle cleaning at Guarulhos airport" (I10), and "free rides for state governors that needed to travel" (I10).

Although the application operates during the pandemic, "the number of drivers was reduced due to this whole situation, so as not to get out of control" (I10).

Company E's platform underwent a digital enhancement due to the pandemic, through the creation of "a space where the driver himself has the autonomy to access the application and send the requested documentation, in order to receive refunds or request support, by proving that he got a positive test result for Covid" (I10). The application gives the feedback, which makes the operation more efficient and quick; previously, drivers had to make the requirements by e-mail. 
Company D also adopted home office for all employees, providing a computer and internet for those who needed it, to keep the speed in answering requests from drivers and passengers, for the service to continue (I10).

The measures implemented by Company $\mathrm{E}$ aimed to reconfigure the business model, to assist drivers more efficiently and keep operations in times of pandemic. Thus, the reduction in the number of drivers and in the number of users during the pandemic (Lima, 2020) supports $P 1$. The incorporation of new functions to the platform, for internal efficiency, supports $P 2 a$. However, there is no evidence that internal efficiency can moderate the crisis's impacts on Company E's businesses. Therefore, $P 2 b$ is not supported.

\section{Discussion}

The results indicate support to the suggested propositions. Except for Company E, which does not meet $P 2 b$, the other unicorns have implemented incremental innovative measures to their business models during the crisis, thus creating changes and opportunities with the available resources (Kuckertz et al., 2020). These regarded three crucial actions: a) adoption of new digital communication platforms to accelerate the information flow; b) strategies to increase the network of partners and meet logistics and execution demands; and c) adaptation in the provision of payment services, as explained below.

(1) Adoption of new digital platforms, for internal and external communication: it enables the speed of information flows and assists compliance of registered customers or those with other links with fintechs (Companies A and D). Companies can incorporate platforms such as Workplace or Slack as soon as they have funds to hire outsourced services, besides creating sites and applications, virtual rooms, quick service buttons, and specialized FAQs (Companies C and D). Adoption of applications (such as the new product launched by Company D) that enable sales through social networks can change other businesses. These platforms allow the company to continue its operations remotely, with a reduced team and a good relationship between customers and partners. Social networks, such as Facebook, Instagram and WhatsApp, stand out as platforms that can be used, even free of charge, to stimulate contact with customers and leverage communication that can reach new audiences (Company D) (Anthony \& Abbas Petersen, 2020; George et al., 2020; Bărbulescu et al., 2021);

(2) Strategies to increase the network of partners and meet logistics and execution demands: partners' networks contribute to transacting costs that technology-based companies would have if they provided services that are outside the scope of their businesses (Amit \& Zott, 2015; Chesbrough, 2010; Priyono et al., 2020). The extension of partnerships is crucial for the internal audience, and allows enjoying several benefits. Regarding the external audience, partnerships enable ways to retain customers and increase benefits when joining a certain service (Companies A and C);

(3) Adaptation in the provision of payment services: it reveals how unicorns have created innovations to keep customers loyal. This adaptation involves creating new forms of payment, flexibilization of interest rates, and, in specific cases (Company D), credit supply for micro-entrepreneurs to keep their businesses. Adaptability is an essential factor for technology-based companies to explore possibilities in different markets, and is a competence that can be refined, depending on how companies define their business models at the time of creation (Cahen \& Borini, 2020). Except for Companies B and E, the others showed 
adaptation strategies for collection and payment, to balance their customers' compliance.

These actions connect to mitigate the pandemic's negative impacts and allow unicorn operations to continue in this scenario. They also are a learning guide for entrepreneurs and SMEs to overcome the crisis by adapting their strategies through the implementation of new practices, changing their business model with the support of digital technologies by recombination, as SMEs have also shown flexibility to make fast adjustments in moments of crisis (Priyono et al., 2020).

Hence, the search for digital transformation is a way for entrepreneurs and SMEs to overcome the crisis and remain active (Priyono et al., 2020), especially by reconfiguring the business model with the support of digital technologies. For many entrepreneurs and SMEs, the easiest way is to adopt "a" and "b" actions, but the acquisition of new products can quickly make the "c" action feasible. However, reconfiguration depends on the company's level of digital maturity.

If a firm is digitally mature, it can accelerate the transition into digitalization; companies that have a low level of digital maturity and problems of liquidity can digitalize only sales, to achieve revenues and get closer to the consumer. Finally, companies with a limited level of digital maturity and high social capital can seek partners with excellent digital resources, such as unicorns, to develop partnerships (Priyono et al., 2020).

This means that the three actions can be taken individually or combined, depending on factors related to the company, such as digital capacity, organizational and learning culture, history, competencies, creativity and management skills (Priyono et al., 2020), entrepreneurial orientation (Ratten, 2020) and type of activity (Soto-Acosta, 2020), among others. More important, companies can choose to reconfigure partially their business model through digital transformation, thus complementing the existing model (Soto-Acosta, 2020).

These actions show that digital BMIs are essential for the survival of companies, mainly in a crisis scenario. The examined BMIs are an alternative to product innovation (Johnson et al., 2008; Amit \& Zott, 2015), and were ex-post, enabling unicorns to expand their services and explore new opportunities in existing markets (Chesbrough, 2010).

This shows that BMI applies to startups and established companies, and highlights the difference between the design of a business model (Sushandoyo et al., 2020) and its fast reconfiguration, recombination (Priyono et al., 2020) or a new configuration (Nunes \& Russo, 2019), to overcome the crisis by choosing less uncertain and costly measures (Massa \& Tucci, 2014; Amit \& Zott, 2015). Therefore, unicorns indicate how adaptable they are to the current scenario, showing competencies for quickly reconfiguring their business model, skills to attract investments and adopt incremental innovations, combining innovations in various dimensions that represent the BMI (Nunes \& Russo, 2019).

Some characteristics stand out in the analyzed companies that allowed digital and incremental BMIs: high capacity to manage and transact costs through technologies (Company A), ability to finance its own solutions (Company D), high capacity to increase digital innovations (Company B), long-term entrepreneurial vision (Company C) and strategic investments (Company E).

These attributes align with startups' overcoming critical factors by identifying opportunities - created by the pandemic, the entrepreneurial commitment; with the reorganization and coordination of resources, including contact with suppliers and customers; with credibility - through the establishment of new partnerships; and with sustainability - owing to continuous innovation (Dalmarco et al., 2017). 
Thus, a new paradigm emerges, linked to startups' process of facing crises, where BMIs show the trade-off between long-term growth and the ability to adapt in times of crisis for implementing innovative short-term solutions, instead of the trade-off between innovation costs and benefits (Johnson et al., 2008; Amit \& Zott, 2015). In any case, this study confirms that BMI through digital reconfiguration (Anthony \& Abbas Petersen, 2020) is essential for the adoption of measures to mitigate pandemic impacts.

\section{Conclusion}

Examining the measures taken by unicorns during Covid-19 crisis shows that we achieved the research objective, in addition to interviewees' reports and secondary data. Among the new measures, we found the creation of new partnership networks, including service outsourcing, payment flexibilization, adaptation of logistics processes, ability to attract external investment and a strong digital improvement of internal operations.

Although most of these companies have a technological base, the pandemic has fostered refinement, digital transformation and innovation capacities. As learning, these companies show that entrepreneurs and SMEs need to develop abilities to innovate in their business models, even partially, and one way for this to happen is through digitalization.

The managerial contribution is the identification of measures that unicorns have adopted, which can serve as a guide or provide insights to entrepreneurs and SMEs, on how to make BMI for overcoming the crisis, by taking, at least, three new actions. These are the adoption of new digital platforms for communication between customers and employees; extension of partners' network; and adaptation for providing payment services. These actions allow the alignment of strategies with BMIs, gradually, through small adaptations in products/services.

As a limitation, we selected for the sample employees that implemented solutions defined by unicorns' high echelon, with the exception of Companies A and B, whose interviewees contributed to develop the measures adopted. To correct and complement this asymmetry, we used secondary data that strengthened the study's evidence.

Future qualitative studies should analyze the BMIs implemented by entrepreneurs and SMEs during the pandemic, and the expected benefits for the subsequent period. In addition, examining what paths were taken for digital change, according to these companies' level of capacity, will assist managers to handle upcoming crises.

\section{References}

Anthony, B., Jr, \& Abbas Petersen, S. (2020). Examining the digitalization of virtual enterprises amidst the COVID-19 pandemic: a systematic and meta-analysis. Enterprise Information Systems, 15(5), $1-34$.

Amit, R., \& Zott, C. (2015). Creating value through business model innovation. MIT Sloan Management Review, 36-44.

Bărbulescu, O., Tecău, A. S., Munteanu, D., \& Constantin, C. P. (2021). Innovation of startups, the key to unlocking post-crisis sustainable growth in Romanian entrepreneurial ecosystem. Sustainability, 13(2), 671. doi: https://doi.org/10.3390/su13020671.

Cahen, F., \& Borini, F. M. (2020). International digital competence. Journal of International Management, 26(1), 100691. doi: https://doi.org/10.1016/j.intman.2019.100691.

CBInsights (2020). The global unicorn club: Current private companies valued at $\$ 1 B+$ (including whisper valuations). Retrieved from https://www.cbinsights.com/research-unicorn-companies 
Chesbrough, H. (2010). Business model innovation: opportunities and barriers. Long Range Planning, 43(2-3), 354-363. doi: https://doi.org/10.1016/j.lrp.2009.07.010.

Cilo, N. (2020). Pandemia do coronavirus: Mercado fitness se reinventa. Estado de Minas. Retrieved from https://www.em.com.br/app/noticia/economia/2020/04/20/internas_economia,1140214/pandemiado-coronavirus-mercado-fitness-se-reinventa.shtml

Condom-Vilà, P. (2020). How technology evolution and disruption are defining the world's entrepreneurial ecosystems: the case of Barcelona's startup ecosystem. Journal of Evolutionary Studies in Business, 5(1), 14-51. doi: https://doi.org/10.1344/jesb2020.1.j067.

Dalmarco, G., Maehler, A. E., Trevisan, M., \& Schiavini, J. M. (2017). The use of knowledge management practices by Brazilian startup companies. RAI Revista de Administração e Inovação, 14(3), 226-234. doi: https://doi.org/10.1016/j.rai.2017.05.005.

De Massis, A., Frattini, F., \& Quillico, F. (2016). What big companies can learn from the success of the unicorns. Harvard Business Review, 1-5.

Dellermann, D., Lipusch, N., Ebel, P., Popp, K. M., \& Leimeister, J. M. (2017). Finding the Unicorn: predicting early stage startup success through a hybrid intelligence method. In International Conference on Information Systems (ICIS), Seoul, South Korea.

García-Gutiérrez, I., \& Martínez-Borreguero, F. J. (2016). The innovation pivot framework: Fostering business model innovation in startups: a new tool helps entrepreneurs design business models by identifying the sources of competitive advantage embedded in an innovation. Research-Technology Management, 59(5), 48-56. doi: https://doi.org/10.1080/ 08956308.2016.1208043.

George, G., Lakhani, K. R., \& Puranam, P. (2020). What has changed? The impact of Covid pandemic on the technology and innovation management research agenda. Journal of Management Studies, 57(8), 1754-1758. doi: https://doi.org/10.1111/joms.12634.

Gornall, W., \& Strebulaev, I. A. (2020). Squaring venture capital valuations with reality. Journal of Financial Economics, 135(1), 120-143. doi: https://doi.org/10.1016/j. jfineco.2018.04.015.

Hogarth, S. (2017). Valley of the unicorns: Consumer genomics, venture capital and digital disruption. New Genetics and Society, 36(3), 250-272. doi: https://doi.org/10.1080/ 14636778.2017.1352469.

Hormiga, E., Xiao, L., \& Smallbone, D. (2018). Entrepreneurial dynamics and institutional changes. Journal of Evolutionary Studies in Business, 3(1), 1-16.

Ingizza, C. (2020). 99 Doa R\$4 mi em corridas Para apoiar cidades na crise da covid-19. Revista Exame. Retrieved from https://exame.abril.com.br/negocios/99-doa-r-4-mi-em-corridas-para-apoiarcidades-na-crise-do-covid-19/

Jinzhi, Z., \& Carrick, J. (2019). The rise of the Chinese unicorn: An exploratory study of unicorn companies in China. Emerging Markets Finance and Trade, 55(15), 3371-3385. doi: https://doi. org/10.1080/1540496X.2019.1610877.

Johnson, M. W., Christensen, C. M., \& Kagermann, H. (2008). Reinventing your business model. Harvard Business Review, 86(12), 57-68.

Ketchen, D. J., Jr, \& Craighead, C. W. (2020). Research at the intersection of entrepreneurship, supply chain management, and strategic management: Opportunities highlighted by COVID-19. Journal of Management, 46(8), 1330-1341. doi: https://doi.org/10.1177/ 0149206320945028.

Krippendorff, K. (2004). Content analysis: an introduction to its methodology, Thousand Oaks, CA: Sage.

Kuckertz, A., Brändle, L., Gaudig, A., Hinderer, S., Reyes, C. A. M., Prochotta, A., . . Berger, E. S. (2020). Startups in times of crisis-a rapid response to the COVID-19 pandemic. Journal of Business Venturing Insights, 13, e00169. doi: https://doi.org/10.1016/j.jbvi.2020.e00169. 
Kudyba, S. (2020). COVID-19 and the acceleration of digital transformation and the future of work. Information Systems Management, 37(4), 284-287. doi: https://doi.org/10.1080/ 10580530.2020.1818903.

Lee, S. M., \& Trimi, S. (2021). Convergence innovation in the digital age and in the COVID-19 pandemic crisis. Journal of Business Research, 123, 14-22. doi: https://doi.org/10.1016/j. jbusres.2020.09.041.

Liguori, E., \& Winkler, C. (2020). From offline to online: Challenges and opportunities for entrepreneurship education following the COVID-19 pandemic. Entrepreneurship Education and Pedagogy, 3(4), 346-351. doi: https://doi.org/10.1177/2515127420916738.

Lima, L. (2020). Efeito COVID-19: 7 a cada 10 usuários deixam de usar aplicativos de transporte. CNN Brasil Business. Retrieved from https://www.cnnbrasil.com.br/ business/2020/04/03/com-coronavirus-7-a-cada-10-usuarios-deixam-de-usar-aplicativosde-transporte

Linnenluecke, M. K. (2017). Resilience in business and management research: A review of influential publications and a research agenda. International Journal of Management Reviews, 19(1), 4-30. doi: https://doi.org/10.1111/ijmr.12076.

Marshall, M. N. (1996). Sampling for qualitative research. Family Practice, 13(6), 522-526. doi: https:// doi.org/10.1093/fampra/13.6.522.

Massa, L., \& Tucci, C. L. (2014). Business model innovation. The Oxford Handbook of Innovation Management, 20(18), 420-441.

Nassif, V. M. J., Corrêa, V. S., \& Rossetto, D. E. (2020). Estão os empreendedores e as pequenas empresas preparadas Para as adversidades contextuais? Uma reflexão à luz da pandemia do Covid-19. Revista de Empreendedorismo e Gestão de Pequenas Empresas, 9(2). doi: https://doi.org/ 10.14211/regepe.v9i2.1880.

Norman, D. A., \& Verganti, R. (2014). Incremental and radical innovation: Design research vs. technology and meaning change. Design Issues, 30(1), 78-96. doi: https://doi.org/10.1162/ DESI_a_00250.

Nunes, M. P., \& Russo, A. P. (2019). Analysis of business models innovation - A multiple case study. Innovation \& Management Review, 16(1), 17-35. doi: https://doi.org/10.1108/INMR-11-20180085.

Priyono, A., Moin, A., \& Putri, V. N. A. O. (2020). Identifying digital transformation paths in the business model of SMEs during the COVID-19 pandemic. Journal of Open Innovation: Technology, Market, and Complexity, 6(4), 104. doi: https://doi.org/10.3390/ joitmc6040104.

Ratten, V. (2020). Coronavirus (covid-19) and entrepreneurship: Changing life and work landscape. Journal of Small Business \& Entrepreneurship, 32(5), 503-516. doi: https://doi.org/10.1080/ 08276331.2020 .1790167$.

Ribeiro, F. (2020). Uber prevê queda de receita de até US\$80 milhões no segundo trimestre. Canal Tech. Retrieved from https://canaltech.com.br/resultados-financeiros/uber-preve-queda-de-receita-deate-us-80-milhoes-no-segundo-trimestre-163531/

Riveira, C. (2020). Sem viagens, reservas de longo prazo no Airbnb sobem 24\% no Brasil. Revista Exame. Retrieved from https://exame.abril.com.br/negocios/fuga-do-coronavirus-reservas-de-longoprazo-no-airbnb-aumentam-no-brasil/

Soto-Acosta, P. (2020). COVID-19 pandemic: Shifting digital transformation to a high-speed gear. Information Systems Management, 37(4), 260-266. doi: https://doi.org/10.1080/ 10580530.2020.1814461.

StartupBase. (2020). Unicórnios brasileiros. Retrieved from https://startupbase.com.br/home/startups? $\mathrm{q}=\&$ states=all\&cities=all\&segments=all\&targets=all\&phases=all\&models=all\&badges $=$ Unic $\%$ C3\%B3rnio 
Sushandoyo, D., Kencanasari, R. A. M., \& Prasetio, E. A. (2020). Distinctive technology and market capabilities for business model innovations in digital startups. Event Proceedings: LUT Scientific and Expertise Publications, ISBN 978-952-335-465-4.

Wirtz, B. W., Pistoia, A., Ullrich, S., \& Göttel, V. (2016). Business models: Origin, development and future research perspectives. Long Range Planning, 49(1), 36-54. doi: https://doi.org/10.1016/j. lrp.2015.04.001.

Yin, R. K. (2015). Estudo de Caso: Planejamento e métodos, Bookman editora.

\section{Corresponding author}

Cristina Doritta Rodrigues can be contacted at: crisdoritta@gmail.com

For instructions on how to order reprints of this article, please visit our website: www.emeraldgrouppublishing.com/licensing/reprints.htm

Or contact us for further details: permissions@emeraldinsight.com 